one but what I have spent some months in his company. And then (alas! that it had not been sooner) I undertook to photograph him.'

The book commences with an account of the early history of the species, as given by Lewis and Clark and subsequent writers; and the author discusses whether the animal ought to be called the grisly (meaning fierce) or grizzly (grey) bear. He decides in favour of the latter, although admitting that Lewis and Clark used grisly (perhaps in the sense of grey), and that Ord gave the name horribilis as the Latin equivalent of grisly in its proper sense. In our own opinion this usage ought to be followed.

To follow the author through his bear-hunting and "bear-snapping" experiences is, in our limited space, impossible, and we must be content in directing attention to the beauty and interest of his photographs of grizzlies in their native wilds. Very interesting, too, are his pictures of the slots of the grizzly and the black bear, showing how widely they differ from one another. The front claws of a grizzly are generally described as being whitish and nearly straight; but the author shows that the latter definition is incorrect, and that they are better described as narrower and less sharply curved than those of other bears.

The book is teeming with interest, and may be cordially recommended to naturalists and sportsmen as a trustworthy account of a disappearing species.

(2) Commendation of a like nature can, we regret to say, scarcely be accorded to the second of the two works forming the subject of this notice. Mr. Percival Westell is a voluminous writer on the fauna of Britain and various groups of invertebrates, but has hitherto, we believe, not tried his hand on mammals as a whole. In the present volume he has attempted to give an account of a selection of the more interesting types of the class, especially those represented in the London Zoological Gardens, arranged according to the nature of their environment, and illustrated with a number of photographs and coloured plates. The photographs are for the most part worthy of all praise, while the execution of the coloured plates is also good, although it is a pity that in some instances-notably the one of the wapiti--the artist was furnished with such poor models.

The volume is confessedly a compilation, largely made up of extracts from the writings of Mr. Seious and two well-known works on natural history-one, by the way, somewhat out of date. When he confines himself to direct extracts from these Mr. Westell does not wander "far from the right path, but when he draws material from his own mind the result is disastrous. We are calmly told, for instance, on p. 245, that, in consequence of the domestication of the species, there are probably no wild yak in Tibet; while from the text and figure on pp. 245 and 246 the author would appear to be labouring under the impression that the cows are hornless. On p. 139 we are informed that it is the brindled, instead of the white-tailed, gnu that is verging on extinction; while from the statement on p. $3^{\text {I4 }}$ it would appear that the author is quite unaware of the existence of the white rhinoceros in Lado and the Bahr-el-Ghazal, where it is not NO. 2 IO2, VOL. 82] in the least danger of extermination. Striped elands (p. r74) are said to occur in northern Africa, where there are no elands at all; Grévy's zebra (p. II4) is stated to have been discovered by Grant and Speke; and the roebuck is affirmed to be a near ally of the muntjac (p. 113). As instances of carelessness we may mention (p. 267) Kabern for Kaberu, and (p. 220) arin for arui. To quote $\mathrm{Mr}$. Ingersoll (p. 242) as the authority for the absence of deer from Ethiopian Africa is about equivalent to referring to Sir Robert Ball as sponsor for the rising of the sun to-morrow morning; while the statement on p. 304 with regard to the distinctness or identity of the European and American beavers is absurd.

Many other blunders and instances of carelessness might be quoted, but the foregoing are sufficient to indicate the untrustworthy nature of $\mathrm{Mr}$. Westell's book.

R. L.

\section{RELIGIO PHYSICI.}

Man and the Universe: a Study of the Influence of the Advance in Scientific Knowledge upon our Understanding of Christianity. By Sir Oliver Lodge, F.R.S. Pp. viii +356 . (London: Methuen and Co., n.d.) Price $7 s .6 d$. net.

$\mathrm{I}$ this vigorous and attractive work Sir Oliver Lodge has gathered into a more or less systematic whole his well-known views upon the relation between science and religion. The result is a "Religio Physici" which recalls its famous prototype as much by contrast as by similarity. Sir Oliver Lodge, like Sir. Thomas Browne, is at once a man of science and a sincere and candid friend to religion, but his apology for this position is far from a mere demonstration that a whimsical temperament can (by a credo quia impossibile est) hold incompatibles in conjunction. Nor does he follow the dangerous precedents of later apologists, who have strained analogies to prove that science and orthodox Christianity, so far from being at loggerheads, are really in perfectly amicable agreement. There is, admits Sir Oliver, "an outstanding controversy" between orthodox men of science and orthodox theologians, "although active fighting has been suspended." The reason for this controversy is "that the attitudes of mind appropriate to these two classes" are "at present fundamentally diverse." Such being the case, the only hope of reconciliation lies in the admission on the part both of man of science and of theologian that neither is in occupation of the sole point of view from which truth is visible. In particular, the man of science must learn

" that it is a sign of unbalanced judgment to conclude, on the strength of a few momentous discoveries, that the whole structure of religious belief, built up through the ages by the developing human race from fundamental emotions and instincts and experiences, is unsubstantial and insecure,

In place of such partisan exclusiveness we must cultivate the conviction that science and religion both contain systems of truth which must ultimately prove to be congruent: "the region of true religion and the region of completer science are one."

In pursuance of this plan of reconciliation, Sir 
Oliver Lodge once more presses upon the physicist his favourite argument (formerly urged in these columns) that the universal operation of formal laws such as the conservation of energy, still leaves room for intelligent "guidance and control"--and may even be compatible with the efficacy of prayer. Further, he recommends more serious attention to the better established data of "psychical research," and the hypotheses as to the nature of human personality based upon them-since both data and hypotheses have an important relation to certain contents of orthodox Christian doctrine. To the theologian he commends a more frank acceptance of the established results of scientific inquiry, counselling him to base his system neither on facts of a negative kind (such as the biologist's present inability to trace the origin of life) nor on single historical events of an alleged miraculous order, but to found it upon the ever-present facts of human nature and experience. The synthesis of this "completer science" with this "true religion" would yield what the author regards and defends as an anthropomorphic pantheism.

Sir Oliver Lodge is evidently aware that professed theologians will regard his work in their department with little more than the politeness due to a distinguished amateur. It is to be feared that the professed philosopher will adopt a similar attitude towards his metaphysics, while, no doubt, there are physicists who remain unconvinced by the doctrine of "guidance." Nevertheless, the book will be read with approval and profit by a great many persons of moderate opinion, who, in matters that affect life as a whole, are disinclined to submit to the tyranny of the departmental expert. Moreover, it will be commended to most readers, not only by the writer's characteristic fairness and sincerity, but also by a tenderly reverent and sometimes eloquent treatment of certain topics unsuitable for specific discussion in this journal.

The reviewer has to express his regret for the late appearance of this notice, for which he alone is responsible.

T. P. N.

\section{MATHEMATICAL PRINCIPLES AND PRACTICE.}

(1) Descriplive Geometry. A Treatise from a Mathematical Standpoint, together with a Collection of Exercises and Practical Applications. By Prof. V. T. Wilson. Pp. viii $+23 \%$ (New York : John Wiley and Sons; London : Chapman and Hall, Ltd., Igo9.) Price 6s, 6d. net.

(2) Practical Arithmetic for Schools. By W. G. Borchardt. Pp. viii $+445+1 x x v i$. (London: Rivingtons, I909.) Price $4 s .6 d$.

(3) The Calculus and its Applications. A Practical Treatise for Beginners, especially Engineering Students. By R. G. Blaine. Pp. ix +32 I. (London: Archibald Constable and Co., Ltd., I909.) Price $4 s .6 d$. net.

(1) DROF. WILSON'S "Descriptive Geometry" is 1 "a treatise from a mathematical standpoint." The author believes that the subject has "suffered mutilation in the interests of short cuts to

NO. 2 IO2, VOL. 82$]$ immediate practical uses," and his aim has been to "refrain from any attempt to hold the student's interest by clothing a few principles with some immediate practical application." From this point of view he has succeeded in producing a sound and excellent work. In the chapters on the point, line and plane, the theorems and principles on which the constructions are based are formally and clearly set out. The scope of the book embraces a general classification of lines and surfaces, including developable surfaces such as the cylinder, cone and convolute; warped surfaces like the hyperbolic paraboloid, conoid, and helicoid; and double curved surfaces, for example, the sphere, ellipsoid, \&ic. The projections, tangencies, intersections and developments of these surfaces are dealt with. "As each new problem is stated, its general solution is first given with reference to the principles involved; and this is followed by a drawing showing the full construction for a particular case; this seems to be an admirable method, conducive to clear thinking and a thorough grasp of the subject.

A collection of exercises and some suggestions for practical applications are provided in the last chapter, and the volume closes with a very complete index. Anyone who has mastered the contents of this book will have no difficulty in applying his knowledge to any practical cases that are ever likely to arise.

(2) The arithmetic by Mr. Borchardt will rank with the best of the recent text-books on the subject. It follows the latest developments, which are now so well known as to render superfluous any detailed description. The requirements of the counting-house, workshop, and laboratory are fully met. The exercises are abundant, carefully graded and of diversified interest, and test papers and copies of recent examination papers are provided. The book is divided into two parts, which may be obtained separately or under one cover, and with or without answers. This school arithmetic cannot fail to give full satisfaction wherever it is used.

(3) "The Calculus and its Applications," by Mr. Blaine, covers a considerable extent of ground, including the differentiation of hyperbolic functions; successive and partial differentiation; maxima and minima of functions of one and two variables; Taylor's theorem; integration by analytical, mechanical and approximate methods; double and treble integrals; differential equations, solutions by symbolic methods; and a chapter on periodic functions and harmonic analysis. The subject is not developed by the author in any very strict logical sequence, and the book is not suitable for beginners working without the aid of a teacher. The principal feature of the work is the large collection of examples illustrating the application of the calculus to practical problems in mensuration, physics, mechanics, and engineering. These are extensively used in the text to explain the significance of the symbols and the operations of the calcalus, and are provided at short intervals as exercises for the student. Teachers will value the book mainly on account of the interest and variety of these practical problems. 